\title{
Long-Lasting Narrowing of the Parent Artery after Bilateral Clipping of Mirror-image Aneurysms of Distal Anterior Cerebral Arteries: A Case Report
}

\author{
Takayuki Mizunari ${ }^{1.2}$, Yasuo Murai ${ }^{1.3}$, Shiro Kobayashi ${ }^{1.2}$, \\ Naoyuki Sakai ${ }^{1,3}$ and Akira Teramoto ${ }^{1,3}$ \\ ${ }^{1}$ Department of Neurosurgery, Graduate School of Medicine, Nippon Medical School \\ ${ }^{2}$ Department of Neurosurgery, Neurosurgical Institute, Nippon Medical School Chiba Hokusoh Hospital \\ ${ }^{3}$ Department of Neurosurgery, Nippon Medical School
}

\begin{abstract}
Because multiple intracranial aneurysms are not rare, accurate preoperative detection of asymptomatic aneurysms is important. In this paper, we report a ruptured distal anterior cerebral artery (DACA) aneurysm associated with an unruptured mirror-image aneurysm in a 62-year-old man presenting with headache. Although delayed vasospasm after subarachnoid hemorrhage has been reported to persist for 2 to 3 weeks, angiographic parent artery narrowing was far more prolonged in our case. Computed tomography revealed a subarachnoid hemorrhage in the interhemispheric and right sylvian fissures and a right frontal lobe hematoma. Digital subtraction angiography demonstrated bilateral symmetric saccular aneurysms of DACAs. On the day of admission, both aneurysms were clipped using an interhemispheric approach in a one-stage procedure, and the hematoma was aspirated. Angiography performed 8 days after the surgery demonstrated a residual aneurysm neck on the left side. Follow-up digital subtraction angiography performed on day 42 from onset showed resolution of the residual aneurysm neck along with narrowing of the left A2. However, at 7 months, the A2 narrowing had lessened. The location of the bilateral aneurysms near the midline facilitated a single approach but necessitated the application of juxtaposed clips. Regarding the pathogenesis of the bilateral aneurysms, previous reports have suggested symmetry of congenital anatomic defects and hemodynamic stress as potential causes. The persistent narrowing that was observed could have resulted from proliferative vasculopathy or from fibrosis possibly induced by the clips.
\end{abstract}

(J Nippon Med Sch 2011; 78: 178-183)

Key words: anterior cerebral artery, cerebral aneurysm, clipping, vasospasms, mirror-image aneurysm, kissing aneurysm

Correspondence to Takayuki Mizunari, MD, Department of Neurosurgery, Nippon Medical School Chiba Hokusoh Hospital, 1715 Kamagari, Inzai, Chiba 270-1694, Japan

E-mail: tmizunari@gmail.com

Journal Website (http://www.nms.ac.jp/jnms/) 


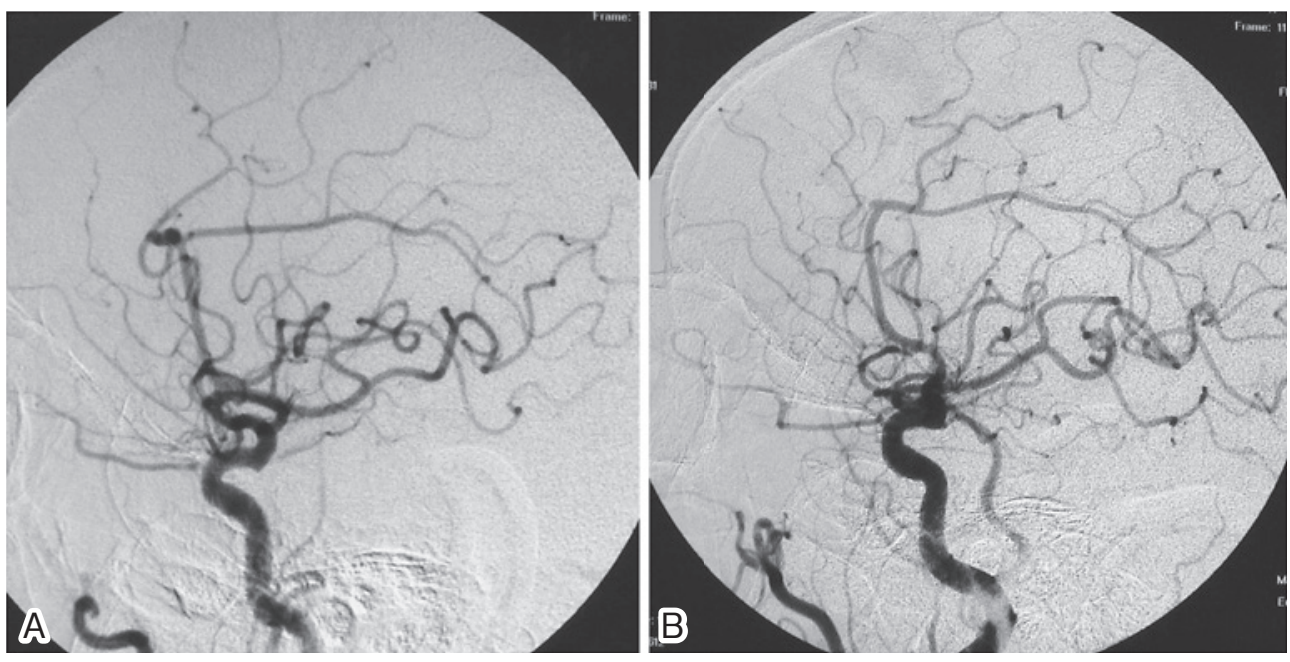

Fig. 1 A: Lateral view of the left ICA angiogram showing a dumbbell-shaped DACA aneurysm. B: Lateral view of the right ICA angiogram showing a small DACA aneurysm.

\section{Introduction}

Delayed vasospasm after a subarachnoid hemorrhage (SAH) can persist for 2 to 3 weeks $^{1-3}$. However, several reports ${ }^{2-7}$ have described cases of delayed ischemic neurological deficit (DIND) that appeared 15 days or more after an aneurysmal SAH. Kawamata et al. $^{4}$ have reported 9 cases of narrowing of the parent artery that was still observed on angiography more than 18 days following aneurysm rupture. Here we report a case of narrowing of the parent artery that was still observed on angiography 3 months after surgery.

The distal anterior cerebral artery (DACA) is the site of $3 \%$ to $5 \%$ of intracranial aneurysms ${ }^{8-10}$. Frequently, other aneurysms are associated with DACA aneurysms ${ }^{10-12}$. Because the interhemispheric operative approach for clipping DACA aneurysms is not typically useful for aneurysms at other sites such as those at the bifurcation of the internal carotid artery (ICA) or the middle cerebral artery (MCA), preoperative localization of other aneurysms is essential ${ }^{10,12}$. In 2002, Sousa et al. $^{13}$ reported on 2 patients with bilateral mirror-image DACA aneurysms and suggested that such cases were extremely rare, with only 1 case $^{9}$ reported before 2001. However, during the preparation of the present report, we found 6 cases that were reported before $2000^{8,9,11,12,14}$. When considered together with the case presented in this paper, these reports offer additional insights, which are discussed below.

\section{Case Presentation}

A 62-year-old man was referred to our hospital because of sudden severe headache. The World Federation of Neurological Surgeons grade at admission was II. Computed tomography (CT) demonstrated an SAH in the interhemispheric and right sylvian fissures and a right frontal lobe hematoma. Digital subtraction angiography (DSA) (Fig. 1A and B) demonstrated bilateral symmetric saccular aneurysms arising from the pericallosal artery at the bifurcation of the callosomarginal artery. The aneurysm at the bifurcation of the left pericallosal artery was irregularly shaped and had a daughter bleb (Fig. 1A). We therefore concluded that the aneurysm on the left side was the aneurysm most likely to rupture. The DSA disclosed no other aneurysms or variant vessels, such as an azygos anterior cerebral artery (ACA), an ACA trifurcation, or a supreme ACA. The bilateral aneurysms, which touched one another, were clipped with an interhemispheric approach in a one-stage procedure. In addition, the hematoma was aspirated.

The postoperative course was uneventful, without symptoms or complications. Angiography performed 


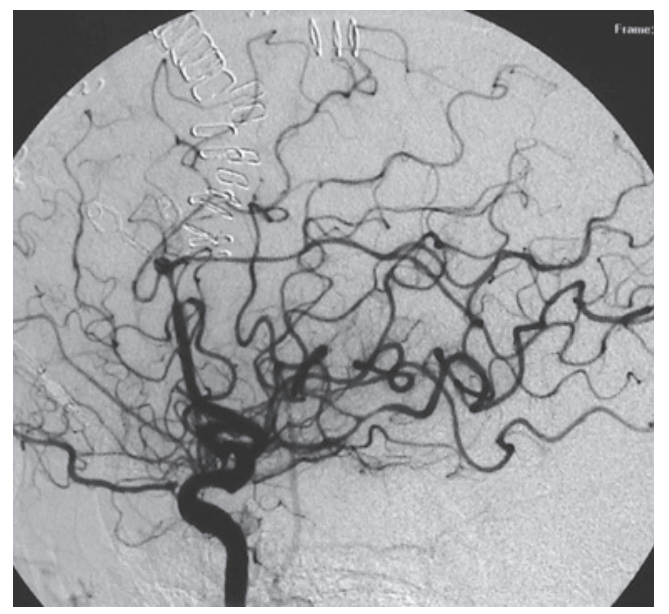

Fig. 2 Lateral view of the left ICA angiogram on day 8 showing the remnant of the aneurysmal neck without vasospasms.

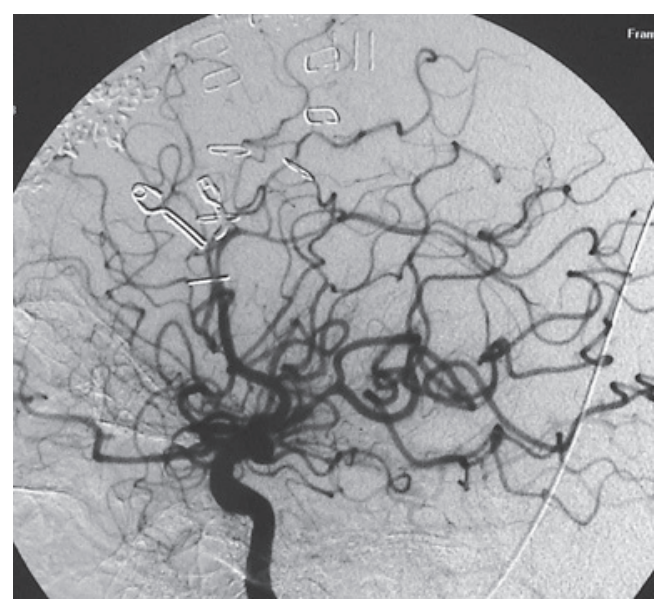

Fig. 3 Lateral view of the right ICA angiogram on day 8 showing complete clipping of the aneurysm without vasospasms.

8 days after the surgery showed a residual aneurysm neck on the left side (Fig. 2), but vasospasm of the A2-A3 portion of ACA was not observed (Fig. 2, 3). The patient was discharged without neurological deficits. We planned an intravascular intervention for coil placement in the residual aneurysm neck but the patient refused the procedure. For treatment planning, left carotid angiography (Fig. 4) was performed 42 days from the. Angiography showed the disappearance (i.e., spontaneous thrombosis) of the residual aneurysm neck along with the narrowing of A2-A3. Treatment was begun with aspirin at a dose of $100 \mathrm{mg} /$ day. Follow-up DSA performed 97 days and at 7 months

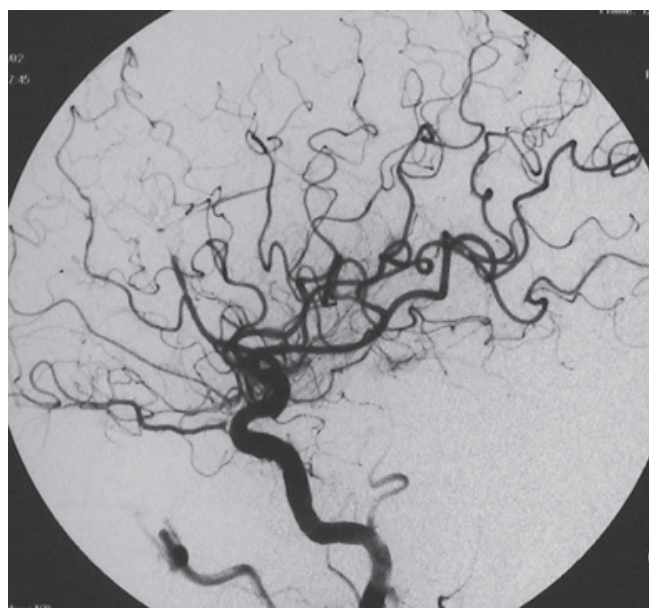

Fig. 4 Lateral view of the left ICA angiogram on day 42 showing no remnants of the aneurysm and severe narrowing of the DACA.

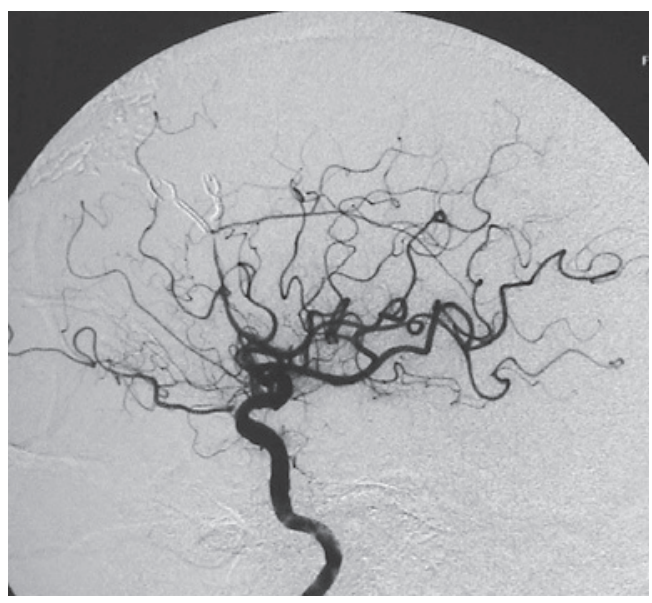

Fig. 5 Lateral view of the left ICA angiogram 7 months after the ictus and showing no remnant of the aneurysm and slight narrowing of the DACA.

(Fig. 5) following the ictus showed delayed partial resolution of the narrowing of the right $\mathrm{A} 2$ without a residual aneurysm neck. There were no further radiological examinations because of the patient's refusal.

\section{Discussion}

\section{Persistent Cerebral Vasospasm or Vessel Narrowing after SAH}

Delayed vasospasm after SAH can persist for 2 to 3 weeks $^{1-3}$, and its etiology remains unclear. To date, only a few $\operatorname{cases}^{4-7}$ have been reported in which a 
DIND had developed more than 15 days after an aneurysmal SAH. Tominaga et al. ${ }^{3}$ have reported 6 such cases and have suggested that meningitis and intracerebral hemorrhage are statistically significant risk factors for DIND with extremely late onset. Yamaguchi et al. $^{7}$ have reported on a patient in whom DIND developed 35 days after SAH, which is the longest reported interval for DIND development. Regarding possible causes of DIND, Yamaguchi et $\mathrm{al}^{7}$ suspected a mass effect remaining in the sylvian fissure after a large hematoma from a ruptured MCA had been aspirated; they recommended continued treatment to prevent cerebral vasospasms until any persisting hematomas were resolved. Taneda et $\mathrm{al}^{2}{ }^{2}$ have also reported a delayed onset of a DIND (16 days). In this patient, a mild ipsilateral DIND occurred on day 8 after surgery for SAH, and the second DIND occurred contralaterally on day 16 . These DINDs were due to the failure to remove a subarachnoid clot. Ohno et al. $^{6}$ have reported on a patient in whom a symptomatic DIND developed 19 days after an SAH and 2 days after surgery. Ohno et al..$^{6}$ have also summarized previously reported cases of DIND after SAH regarding the timing of DIND onset. In only $0.6 \%$ patients did symptomatic DIND develop more than 16 days after SAH. In our case, a small subarachnoid clot was observed intraoperatively, but no intracerebral hematomas were detected with postoperative CT. Kawamata et al. ${ }^{4}$ have observed a prolonged angiographic cerebral vasospasm more than 18 days after aneurysm rupture in 9 cases. In our case, angiographic vasospasm persisted for more than 3 months. Kondziolka et al..$^{5}$ have reported 3 cases of DIND with angiographic evidence of cerebral arterial luminal narrowing that was observed 7,14 , and 52 weeks after SAH; they hypothesized that arterial narrowing observed months after SAH suggest proliferative vasculopathy as opposed to prolonged active constriction of the vascular smooth muscle ${ }^{5}$. In the third case reported by Kondziolka ${ }^{5}$ and in our present case, luminal narrowing of a cerebral artery was shown directly adjacent to the clip. Although such narrowing near a clip may represent physiological vasospasm, iatrogenic arterial injury from the clip may have occurred. In our case, the aneurysm clip on one side may have compressed or abraded the parent artery of the other aneurysm. Commenting upon Kondziolka's third case ${ }^{5}$, Shiokawa et al. ${ }^{1}$ have speculated that clip-induced fibrosis contributes to stenosis of a parent artery. Prolonged narrowing of the parent artery thus may reflect important technical difficulties resulting from the clipping of symmetrical bilateral DACA aneurysms.

\section{Mirror-image DACA Aneurysms}

An interhemispheric approach for treating DACA aneurysms is not useful for treating additional aneurysms at other sites, such as those at the bifurcation of the ICA or MCA. Accurate preoperative detection and localization of all additional aneurysms is, therefore, extremely important $t^{12,15}$. Including the present case, 10 cases of bilateral mirror-image DACA aneurysms have been reported $^{8.911-14}$ (Table 1). Four patients were men, and 9 patients presented with an SAH from 1 of a pair of DACA aneurysms. In 6 cases, a third aneurysm was observed. Only 1 case showed a variant vessel, such as a supreme ACA. The pathogenesis of aneurysms may be multifactorial, but a prominent factor in aneurysm development is hemodynamic stress at the arterial bifurcation. Casimiro et al..$^{16}$ have reported that risk factors differ between mirrorimage and other types of multiple aneurysms. Casimiro et al. ${ }^{16}$ have noted relatively young ages at presentation and a general lack of known risk factors for intracranial aneurysms in patients with mirror-image multiple aneurysms. The report of Casimiro et al. $^{16}$ and 2 other reports ${ }^{9.17}$ have hypothesized that patients with mirror-image aneurysms may have a localized congenital predisposition to vessel fragility or vascular wall defects, which may lead to early rupture in the absence of other risk factors. However, Casimiro et al. ${ }^{16}$ did not analyze whether any of the risk factors was associated with different locations of mirrorimage aneurysms, such as the DACA, ICA, or MCA.

Surgical treatment of aneurysms, such as the one reported, requires special consideration in the dissection of the interhemispheric fissure and the detection of the ruptured aneurysm ${ }^{18.19}$. Yasargil et 
Table 1 Summary of reported cases of bilateral DACA aneurysms

\begin{tabular}{lcccllc}
\hline \multicolumn{1}{c}{ Author } & $\begin{array}{c}\text { Age } \\
\text { (years) }\end{array}$ & Sex & $\begin{array}{c}\text { Rupture of DACA } \\
\text { aneurysm }\end{array}$ & $\begin{array}{l}\text { Another } \\
\text { aneurysm }\end{array}$ & Vascular anomaly & $\begin{array}{c}\text { Glasgow } \\
\text { Outcome Scale }\end{array}$ \\
\hline Wisoff 12 & 60 & $\mathrm{M}$ & rupture & Unknown & unknown & MD \\
Wisoff & 55 & $\mathrm{M}$ & rupture & IC & unknown & GR \\
Sousa $^{13}$ & 65 & $\mathrm{~F}$ & rupture & IC-Pcom & none & GR \\
Sousa $_{\text {Mori }}{ }^{9}$ & 55 & $\mathrm{~F}$ & rupture & None & none & D \\
Niijima $^{17}$ & 43 & $\mathrm{~F}$ & rupture & None & none & GR \\
Kawamata $^{4}$ & 67 & $\mathrm{~F}$ & rupture & None & none & GR \\
Kuroiwa $^{14}$ & 57 & $\mathrm{~F}$ & rupture & None & supreme ACA & D \\
Kodoya $^{11}$ & 52 & $\mathrm{~F}$ & rupture & MCA & none & GR \\
Present & 64 & $\mathrm{M}$ & nonrupture & MCA & none & GR \\
\hline
\end{tabular}

Abbreviations

F, female; M, male; DACA, distal anterior cerebral artery; ICA, internal carotid artery; Pcom, posterior communicating artery; MCA, middle cerebral artery; GR, good recovery; MD, moderate disability; D, death.

al. $^{10}$ have indicated that the surgical clipping of DACA aneurysms is technically difficult for the following reasons: the possible presence of multiple aneurysms, the narrow subarachnoid space in the region being exposed with the interhemispheric approach, and the broad base of the aneurysms. The numerous reports ${ }^{8,10,13,18,20}$ of mirror-image or bilateral DACA aneurysms have also emphasized that the dissection of the interhemispheric fissure or cisterns and the retraction of the medial surface of the frontal lobe away from an aneurysm on one side may cause a contralateral mirror-image aneurysm to rupture $^{18-21}$. In addition, determining the location, or even the side, of a ruptured aneurysm is often difficult $^{19}$. Therefore, surgeons must rely on careful preoperative studies, such as CT scans, digital subtraction angiography, magnetic resonance angiography, and 3-dimensional CT angiography, to determine the location of a ruptured aneurysm. A different surgical problem in our case was that the heads of the 2 opposing clips abutted. This abutting may have resulted in a failure to promptly obliterate the neck of 1 of the aneurysms.

\section{References}

1. Shiokawa Y, Aoki N, Saito I: Delayed ischemic deficit after SAH and aneurysm clipping. J Neurosurg 1989; 70: 970-971.

2. Taneda M, Wakayama A, Ozaki K, Kataoka K, Hayakawa T, Mogami H: Biphasic occurrence of delayed ischemia after early aneurysm surgery. Case report. J Neurosurg 1983; 58: 440-442.

3. Tominaga J, Shimoda M, Oda S, et al.: Delayed ischemic neurological deficit that developed over 15 days after subarachnoid hemorrhage. No Shinkei Geka 1998; 26: 135-140 (Japanese).

4. Kawamata T, Aoki N, Sakai T, Arai K: Symptomatic cerebral vasospasm manifested 18 days after aneurysmal subarachnoid haemorrhage. Neurol Res 1993; 15: 209-211.

5. Kondziolka D, Bernstein M, Spiegel SM, ter Brugge $\mathrm{K}$ : Symptomatic arterial luminal narrowing presenting months after subarachnoid hemorrhage and aneurysm clipping. J Neurosurg 1988; 69: 494499.

6. Ohno K, Masaoka H, Suzuki R, Monma S, Matsushima Y: Symptomatic cerebral vasospasm of unusually late onset after aneurysm rupture. Acta Neurochir (Wien) 1991; 108: 163-166.

7. Yamaguchi M, Bun T, Kuwahara T, Kitamura S: Very late-onset symptomatic cerebral vasospasm caused by a large residual aneurysmal subarachnoid hematoma-case report. Neurol Med Chir (Tokyo) 1999; 39: 677-680.

8. Kawamata T, Suzuki Y, Matsumoto H, Ozawa H, Matsumoto K: Bilateral distal anterior cerebral artery aneurysm associated with supreme anterior cerebral artery: case report. No Shinkei Geka 1999; 27: 341-346 (Japanese).

9. Mori T, Fujimoto M, Shimada K, Shin H, Sakakibara T, Yamaki T: Kissing aneurysms of distal anterior cerebral arteries demonstrated by magnetic resonance angiography. Surg Neurol 1995; 43: 497499.

10. Yasargil MG, Carter LP: Saccular aneurysms of the distal anterior cerebral artery. J Neurosurg 1974; 40: 218-223.

11. Kadoya C, Momota Y, Urasaki E, Wada S, Yokota A: Double bilateral symmetrical aneurysms - case report. Neurol Med Chir (Tokyo) 1994; 34: 35-37.

12. Wisoff JH, Flamm ES: Aneurysms of the distal anterior cerebral artery and associated vascular 
anomalies. Neurosurgery 1987; 20: 735-741.

13. Sousa J, Iyer V, Roberts G: "Mirror image" distal anterior cerebral artery aneurysms. A case report of two patients with review of literature. Acta Neurochir (Wien) 2002; 144: 933-935.

14. Kuroiwa T, Tanabe H, Takatsuka H, et al.: Bilateral distal anterior cerebral artery aneurysms associated with polycystic kidney and liver disease; a case report. No Shinkei Geka 1992; 20: 905-908 (Japanese).

15. Sakakibara Y, Taguchi Y, Ide M, Oshio K, Hiramoto $\mathrm{J}$, Onodera H: A case of ruptured internal carotid artery "kissing aneurysms": case report and review of the literature. No Shinkei Geka 2006; 34: 297-303 (Japanese).

16. Casimiro MV, McEvoy AW, Watkins LD, Kitchen $\mathrm{ND}$ : A comparison of risk factors in the etiology of mirror and nonmirror multiple intracranial aneurysms. Surg Neurol 2004; 61: 541-545.

17. Niijima KH, Yonekawa Y, Kawano T: Bilateral pericallosal artery aneurysms in a mirror position. No Shinkei Geka 1989; 17: 779-781 (Japanese).

18. Sorimachi T, Fujii Y, Nashimoto T, Morita K: Kissing aneurysms at the junction of the internal carotid artery and the ipsilateral duplicate anterior choroidal arteries - case report. Neurol Med Chir (Tokyo) 2006; 46: 29-31.

19. Wanifuchi H, Shimizu T, Higa T, Nakaya K: Kissing mirror image anterior communicating artery aneurysms-case report. Neurol Med Chir (Tokyo) 2001; 41: 29-32.

20. Im SH, Kwon BJ, Jung C, Seo HS, Lee DH, Han MH: Coil embolization of "kissing aneurysms" associated with distal basilar artery fenestration. Clin Neurol Neurosurg 2007; 109: 210-213.

21. Yamada K, Nakahara T, Kishida K, Yano T, Yamamoto K, Ushio Y: Multiple "mirror" aneurysms involving intracavernous carotid arteries and vertebral arteries: case report. Surg Neurol 2000; 54: 361-365.

(Received, October 30, 2010)

(Accepted, January 14, 2011) 